\title{
Complying with the framework convention for tobacco control: an application of the Abridged SimSmoke model to Israel
}

\author{
David Levy ${ }^{1}$, David B. Abrams ${ }^{1,2}$, Jeffrey Levy ${ }^{3}$ and Laura Rosen ${ }^{4 *}$
}

\begin{abstract}
Background: The World Health Organization Framework Convention for Tobacco Control (FCTC) established the MPOWER policy package to provide practical country-level guidance on implementing effective policies to reduce smoking rates. The Abridged SimSmoke tobacco control policy simulation model is applied to Israel to estimate the effects on reducing smoking-attributable mortality resulting from full implementation of MPOWER policies.

Methods: Smoking prevalence from the 2014 Israel National Health Interview Survey 3 and population data from the Israel Central Bureau of Statistics were used to calculate the number of current smokers. The status of current Israeli policy was determined using information from MPOWER 2015 and from local sources. Based on existing knowledge that between $50 \%$ and $65 \%$ of smokers will die prematurely from smoking, the model is used to determine mortality reductions among current smokers from full implementation of MPOWER policies.

Results: We estimate that between 550 and 710 thousand smokers of the current 1.1 million Israeli smokers will prematurely die due to smoking. Within 40 years, complete implementation of MPOWER policies is projected to reduce smoking prevalence among current smokers by $34 \%$ and avert between 188 and 245 thousand deaths among current smokers. Taxes, smoke-free air laws, marketing restrictions and media campaigns each reduce smoking by about $5 \%$ within 5 years. Improved cessation treatment and health warnings each have smaller effects in the next five years, but their effects grow rapidly over time.

Conclusions: Israel Abridged SimSmoke shows that complete implementation of the MPOWER strategies has the potential to substantially reduce smoking prevalence, and avert premature deaths due to smoking. Additional benefits are also expected from reduced morbidity, reduced initiation among nonsmokers, and reduction in exposure of nonsmokers to tobacco smoke.
\end{abstract}

Abbreviations: FCTC, Framework convention for tobacco control; MPOWER, WHO package to implement the FCTC; WHO, World Health Organization

\section{Background}

To reduce non-communicable deaths, the World Health Organization (WHO) set a voluntary target of a $30 \%$ reduction in smoking rates by 2025 as part of its global Non-Communicable Disease agenda [1]. In addition, the WHO launched a policy package that focuses on selected demand side measures for tobacco products, MPOWER, in 2008 [2]. This package recommends the following

\footnotetext{
* Correspondence: rosenl@post.tau.ac.il

${ }^{4}$ Department of Health Promotion, School of Public Health, Sackler Faculty of Medicine, Tel Aviv University, Ramat Aviv, Israel

Full list of author information is available at the end of the article
}

policies: Monitor tobacco use and prevention policies, Protect people from tobacco smoke, Offer help to quit tobacco use, Warn about the dangers of tobacco, Enforce bans on tobacco advertising, promotion and sponsorship, and Raise taxes on tobacco. The magnitude of the effect of each MPOWER policy on smoking prevalence varies and depends on the policies implemented, how they are implemented, and the country-level policies that were previously in effect [3].

The Simsmoke Tobacco Control Policy simulation model has been used to estimate the impact of past policies and potential impact of implementing stronger MPOWER 
policies on smoking prevalence and smoking-attributable deaths among current smokers within a country or state [4-10]. This model projects the smoking rates over time with the birth and deaths, and the initiation and cessation of smokers. The model predicts well by age and gender for countries that have and have not implemented many strong policies [5-11]. In a previous application [10], we developed a simplified form of SimSmoke, Abridged SimSmoke, to evaluate the results of implementing past MPOWER-required policies on country-level reductions in smoking-related deaths. A later paper [12] extended Abridged SimSmoke to show the effect of implementing future policies in accordance with MPOWER requirements. The model calculates the impact of the policies on current smokers only, and does not address those who have not yet begun smoking.

The data requirements for Abridged SimSmoke are less than for the original SimSmoke and parallel the smoking prevalence and policy data collected for the biennial WHO MPOWER/WHO Report on the Global Tobacco Epidemic [1]. Like SimSmoke, Abridged SimSmoke projects changes in smoking prevalence and smokingattributable deaths resulting from the implementation of MPOWER policies. We apply that model to Israel.

Israel ratified the FCTC in August 2005 (apps.who.int/ fctc/implementation/database/parties/Israel) [13]. Previously, Israel had implemented multiple tobacco policies including taxation (beginning in 1952 and since expanded), smoke-free air policies (beginning in 1982 and since expanded), restrictions on advertising (beginning in 1983 and since expanded), and health warnings (beginning in 1983 and since expanded). Since signing the FCTC, Israel has legislated and implemented stronger smoke-free air laws and began to subsidize cessation treatment through the National Basket of Services. However, despite the passage of the National Plan for Reduction of Smoking and its Harms in 2011, which was based in part on the FCTC and MPOWER, Israel does not yet meet the complete MPOWER requirements for any of the six recommended MPOWER policies [13, 14]. For example, smoke-free regulations are not well enforced [13, 15-20] he planned comprehensive ban on advertising, promotion, and marketing did not pass into legislation, and there is no targeted budget for media campaigns or other tobacco control activities [13].

In this paper, we present the results of the Abridged SimSmoke applied to Israel. We estimate the effects of implementing the policies meeting the FCTC-MPOWER requirements on smoking prevalence and smokingattributable deaths among current smokers in Israel.

\section{Methods}

Abridged SimSmoke uses data from a single year to project short-term (5 years) and long-term (40 years) effects on smoking prevalence. It is similar to the original SimSmoke in that it relies on population size smoking prevalence and policy modules to make predictions. Abridged SimSmoke also uses formulas similar to SimSmoke to show a reduction in smoking prevalence in each policy module. Therefore, Abridged SimSmoke predicts the effect of individual and combined policies on smoking prevalence and the number of smokers, which is used to project the number of smoking-attributable deaths among smokers alive in 2014.

\section{Smokers and smoking-attributable deaths}

First, the number of smokers, by gender, is obtained by multiplying the respective smoking prevalence and the corresponding population size. Population data for 2014 is from Table 2.5 of the Israel Central Bureau of Statistics. Smoking prevalence (ages 20 and above) is from the most recent nationally representative survey, the 2014 Israel National Interview Health Survey 3, with sample size 2774 [21]. The weighted prevalence rate of smokers was $24.5 \%$ for men and $13.2 \%$ for women.

The number of deaths attributable to smoking is determined using a formula based on the relative risks of smoking. Doll et al [22] concluded that "half of all regular cigarette smokers will eventually be killed by their habit". Recent studies [23, 24] found that about $65 \%$, rather than half, of current smoker deaths are attributable to smoking. Upper and lower estimates of deaths expected are calculated by applying the estimates of $50 \%$ and $65 \%$, respectively. Applying the relevant policy effect sizes, we calculate the expected reduction in smokers and deaths as result of a specific policy or group of policies.

\section{Policy levels and effect sizes}

Abridged SimSmoke uses SimSmoke policy effect size estimates, which are based on literature reviews, the advice of expert panels, and model validation $[4,5,10,25,26]$. For each policy, the effect size, is applied as a percentage reduction in smoking prevalence. An urban adjustor, measured as $[1 \%$ employed in agriculture], and the percent not in the labor force, are applied to the work-site effect size, to reflect that smoke-free work-site laws primarily influence the population who work indoors. Israel had $2 \%$ of workers in agriculture [27] and a labor participation rate of $60 \%$ for women and $70 \%$ for men [28].

Based on SimSmoke, a long-term multiplier is estimated for each policy as the ratio of the relative change in prevalence (after 40 years) to the relative change in short-term prevalence (after 5 years). This method is applied to the MPOWER policies. These policies are described and their effect sizes listed in Table 1, with upper and lower bound ranges provided in terms of percentage increases and reductions in effect size. 
Table 1 Policies, specifications and effect sizes used in abridged SimSmoke

\begin{tabular}{|c|c|c|c|c|c|}
\hline Policy & Description & $\begin{array}{l}\text { Effect size } \\
(\% \text { Effect })^{a}\end{array}$ & $\begin{array}{l}\text { Ranges for sensitivity } \\
\text { analysis }^{\mathrm{a}}\end{array}$ & $\begin{array}{l}\text { Long term } \\
\text { multi-plier }^{a}\end{array}$ & $\begin{array}{l}\text { Urban } \\
\text { adjustor }^{b}\end{array}$ \\
\hline $\begin{array}{l}\text { Tax as a percent of retail } \\
\text { price of cigarettes }\end{array}$ & $\begin{array}{l}\text { Excise tax, taking into } \\
\text { account expanded effect } \\
\text { through value added tax }\end{array}$ & $\begin{array}{l}5.9 \% \text { (with price elasticity }-0.15^{c} \\
\text { and tax as a percent of price } \\
\text { increasing from } 69 \% \text { to } 75 \% \text { ) }\end{array}$ & $(-25 \%-+25 \%)$ & 2 & no \\
\hline \multicolumn{6}{|l|}{ Smoke-free air laws } \\
\hline $\begin{array}{l}\text { Ban in all indoor } \\
\text { workplaces }\end{array}$ & $\begin{array}{l}\text { Ban in all indoor private } \\
\text { workplaces }\end{array}$ & $6 \%$ & $(-50 \%,+50 \%)$ & 1.25 & yes \\
\hline Ban in indoor offices only & $\begin{array}{l}\text { Ban except ventilated } \\
\text { workplaces }\end{array}$ & $4 \%$ & $(-50 \%,+50 \%)$ & 1.25 & yes \\
\hline $\begin{array}{l}\text { Ban in health facilities, univ, } \\
\text { govt. facilities ( } 2 \text { of } 3)\end{array}$ & Ban in work areas only & $2 \%$ & $(-50 \%,+50 \%)$ & 1.25 & yes \\
\hline $\begin{array}{l}\text { Restaurants: Smoke-free } \\
\text { in all indoor areas }\end{array}$ & Ban in restaurants & $2 \%$ & $(-50 \%,+50 \%)$ & 1.25 & yes \\
\hline Pubs and bars: smoke-free & Ban in pubs and bars & $1 \%$ & $(-50 \%,+50 \%)$ & 1.25 & yes \\
\hline Enforcement & MPOWER: 0-10 & $\begin{array}{l}25 \% \text { of effect depends on } \\
\% \text { enforcement (of 10) }\end{array}$ & & & \\
\hline Publicity & $\begin{array}{l}\text { Based on level of tobacco } \\
\text { control funding }\end{array}$ & $\begin{array}{l}25 \% \text { of above effect } \\
\text { depends on publicity }\end{array}$ & & & \\
\hline \multicolumn{6}{|c|}{ Mass Media Campaigns (policies are mutually exclusive) } \\
\hline $\begin{array}{l}\text { Highly publicized } \\
\text { campaign }\end{array}$ & $\begin{array}{l}\text { Tobacco control spending } \\
\geq \$ 0.50 \text { USD per capita \& } \\
\text { media campaign }\end{array}$ & $6.5 \%$ reduction & $(-50 \%,+50 \%)$ & 1.2 & no \\
\hline Moderately publicized campaign & $\begin{array}{l}\text { Tobacco control spending } \\
\geq \$ 0.05 \text { and }<\$ 0.50 \text { USD } \\
\text { per capita }\end{array}$ & $3.5 \%$ reduction & $(-50 \%,+50 \%)$ & 1.2 & no \\
\hline Low publicized campaign & $\begin{array}{l}\text { If tobacco control spending } \\
<\$ 0.05 \text { USD per capita }\end{array}$ & $1.0 \%$ reduction & $(-50 \%,+50 \%)$ & 1.2 & no \\
\hline \multicolumn{6}{|l|}{ Marketing Bans $^{d}$} \\
\hline $\begin{array}{l}\text { Ban on direct and indirect } \\
\text { marketing }\end{array}$ & $\begin{array}{l}\text { Ban on all direct and indirect } \\
\text { advertising }\end{array}$ & $5 \%$ & $(-50 \%,+50 \%)$ & 1.3 & no \\
\hline Ban on advertising & Ban on all direct advertising & $3 \%$ & $(-50 \%,+50 \%)$ & 1.3 & no \\
\hline Partial ban on advertising & $\begin{array}{l}\text { Ban on some direct or } \\
\text { indirect advertising }\end{array}$ & $1 \%$ & $(-50 \%,+50 \%)$ & 1.3 & no \\
\hline Enforcement & MPOWER: 0 - 1.0 & $\begin{array}{l}50 \% \text { of effect depends } \\
\text { on enforcement }\end{array}$ & & & \\
\hline \multicolumn{6}{|l|}{ Health Warnings ${ }^{d}$} \\
\hline Complete & $\begin{array}{l}\text { Bold and graphic, covers } \\
50 \% \text { of package }\end{array}$ & $2 \%$ & $(-50 \%,+50 \%)$ & 2 & no \\
\hline Strong & Warning $30-50 \%$ of package & $1 \%$ & $(-50 \%,+50 \%)$ & 2 & no \\
\hline Weak & Warning $<30 \%$ of package & $0.50 \%$ & $(-50 \%,+50 \%)$ & 2 & no \\
\hline \multicolumn{6}{|c|}{ Cessation Treatment Policies ${ }^{\mathrm{e}}$} \\
\hline $\begin{array}{l}\text { Nicotine Replacement } \\
\text { Therapy }\end{array}$ & $\begin{array}{l}\text { If sold by pharmacy or general } \\
\text { store and if Rx required }\end{array}$ & $\begin{array}{l}\text { Prev. reduced } 0.667 \% \text { if } \\
\text { available at w/out Rx, } \\
0.334 \% \text { if Rx }\end{array}$ & $(-75 \%,+75 \%)$ & 2.5 & yes \\
\hline Bupropion and Varenicline & $\begin{array}{l}\text { Sold by pharmacy with } \\
\text { prescription }\end{array}$ & Prev. reduced $0.334 \%$, & $(-75 \%,+75 \%)$ & 2.5 & yes \\
\hline Provision of treatments & $\begin{array}{l}\text { Type facilities: primary care, } \\
\text { hospitals, health professionals, } \\
\text { community and other }\end{array}$ & $\begin{array}{l}\text { If provided in in most, } \\
\text { prevalence reduced } 2.25 \% \text {, } \\
\text { if provided in some, } \\
\text { then } 1.125 \%\end{array}$ & $(-75 \%,+75 \%)$ & 2.5 & yes \\
\hline
\end{tabular}


Table 1 Policies, specifications and effect sizes used in abridged SimSmoke (Continued)

\begin{tabular}{|c|c|c|c|c|c|}
\hline Quit line type & Operating active quit line & Prev. reduced $0.5 \%$ & $(-75 \%,+75 \%)$ & 2.5 & yes \\
\hline Overall effect & $\begin{array}{l}\text { With all of the above policies } \\
\text { and publicity based on } \\
\text { tobacco control funding }\end{array}$ & $\begin{array}{l}\text { Prev. reduced } 4.75 \% \text {, } \\
25 \% \text { of effect depends } \\
\text { on publicity }\end{array}$ & $(-75 \%,+75 \%)$ & 2.5 & yes \\
\hline
\end{tabular}

Notes: HIC high-income country, LIC low-income country, MIC middle-income country, NA not applicable, NRT nicotine replacement therapy

${ }^{a}$ Short-term effect size is defined as the relative percentage change in smoking prevalence in first five years of policy implementation. The long-term effect is short-term-effect multiplied by the long-term multiplier, adjusted by awareness and urban status adjustors. We also provide ranges for the effect sizes, which are measured as percentage variation in the effect sizes compared to the level in the preceding column

${ }^{\mathrm{b}}$ The urban adjustor reduces the effect to reflect the percentage of the rural population not affected by the policies indicated

'See Levy et al [32] for a description of the calculations

${ }^{\mathrm{d}}$ Categories are mutually exclusive categories

${ }^{e}$ Effects are additive over policies

The effect of implementing stronger policies depends on the initial level of policies. For example, the effect of further marketing restrictions (e.g., in compliance with MPOWER) will be less for a country that already has extensive restrictions than for a country without any marketing restrictions. Data on the level of each policy is from the most recent MPOWER reports [1] and Rosen [13].

Three types of smoke-free air policies (as applied to worksites, restaurants and bars, and other public places) are included in Abridged SimSmoke, with the effect of worksite bans further distinguished by their stringency: 1) partial, as designated by a ban in 2 of the 3 following types of facilities: health, university, and government facilities, 2) a ban in indoor offices only, and 3) a ban in all indoor workplaces. The effects are halved in the absence of publicity (based on tobacco control campaign spending as described below) and complete enforcement (an index based on MPOWER reports from 1 to 10 , where $10=$ complete enforcement). Smoke-free legislation in public places was first introduced in Israel at the national level in 1982 and was expanded over the years to include public transportation, cinemas, theatres, educational institutions, and workplaces, among others; however, the only places to be mandated as $100 \%$ smoke-free were health-care facilities. In 2007, smoke-free legislation (P) shifted from restriction to prevention, with increasing fines and liabilities for owners. In 2012, the ban was extended to youth centers, nursing homes, religious institutions, all government buildings, and some outdoor public areas [13]. Rather than $100 \%$ smoke-free workplaces, smoking is permitted in private offices in nongovernmental buildings. In addition, bars, and pubs are permitted to set aside a quarter of their space for smokers as long as it is in a separate room. There are fines for violations on the establishment owners and patrons, but they are inconsistently enforced. When citizen complaints are registered, investigations are undergone but are, likewise, inconsistent in scope and regularity. In Dec. 2015, a new regulation was passed in the Knesset which stipulated that all schools be entirely smoke-free, effective in January 2016. The level of restrictions is set at $50 \%$ for worksites, restaurants and bars and other public places, and compliance is set at level 3 out of 10 in the MPOWER Reports, as it is a well-known problem $[19,20,29,30]$.

MPOWER cessation treatment has three sub-policies: pharmacotherapy (PT) availability, financial coverage of treatments, and quit lines. Quit lines reflect the presence of a national quit line. Israel does not have a national quit line, however, two of its four HMOs have quit lines, and the Israel Cancer Association provides information by telephone. In 2010, smoking cessation technologies were added to the National Basket of Services. Free smoking cessation workshops were made available and Varencline, and Zyban became subsidized, contingent on attendance at the cessation workshops. Nicotine Replacement Therapy, (NRT) which has been available over the counter, was added in 2015 as a second-line medication, in case a smoker was unable to use Varenicline or Zyban. Attempts to add individual and phone counseling have been unsuccessful [13].

Health warnings on packs has four policy levels: none, minimal ( $<30 \%$ of the principal display area of the pack), moderate (a warning covering at least $30 \%$ of the principal display area of the pack, and meets 1 to 7 of the seven pack warning criteria), and complete (a warning that covers at least $50 \%$ of the principal display pack area and includes all seven pack warning criteria, including graphic warnings, as well as a ban on deceitful terms). According to the 2014 MPOWER Report, Israel has a moderate policy, as the warning covers $30 \%$ of the principal display area of the pack and meets several pack warning criteria. In addition to health warnings, MPOWER includes media campaigns as an education policy. SimSmoke rates media campaigns based on the existence of a media campaign and funding levels specified for tobacco control. MPOWER reports do not report expenditures for Israel, but indicate no national campaign. Further, there is currently no dedicated budget for tobacco control [13]. With few staff devoted 
to tobacco control, media campaigns are categorized as at a low level.

Four levels of marketing restriction policies are designated: none, minimal, moderate, and comprehensive restrictions. They include restrictions on advertising as well as marketing practices, such as branding and sponsorship. For marketing restrictions, no enforcement will reduce the impact of the policy by half. According to the MPOWER Report, Israel has a minimal policy for marketing restrictions, as two out of eight areas are bans on direct advertising and three out of fifteen are bans on indirect advertising, ranked 2 out of 4 (minimal). For direct advertising, Israel has a ban on national TV and radio and fines for violating this ban, but does not have bans on magazines and newspapers, billboards and outdoor advertising, point of sale advertising, and the internet. For bans on indirect advertising, Israel has bans on free distribution in mail or through other means, appearance of tobacco brands in TV and/or film (product placement) and fines for violating these bans, but does not ban promotional discounts, non-tobacco goods or services identified with tobacco brand names, brand names of non-tobacco goods or services used for tobacco products, appearance of tobacco products in TV and/or films, sponsored events, display at point of sale, bans on the tobacco or other industries publicizing their activities, bans on tobacco companies funding or making contributions to smoking prevention media campaigns including those directed at youth, and a requirement to present prescribed antitobacco ads before, during, or after the broadcasting or showing of any visual entertainment. According to the MPOWER reports, Israel has advertising restrictions ranked as level 2 out of 4 in the MPOWER Reports. Compliance is at level two of 10 .

Cigarette taxation affects cigarette price which, in turn, influences cigarette use. Taxes are specified as a percent of the retail cigarette price. In accordance with MPOWER policies, we consider the effect of increasing excise taxes (including ad valorem taxes or specific (per unit) taxes directly on cigarettes) to $75 \%$ of price. The value added tax (VAT) applies to all goods, not just cigarettes, but amplifies the effect of an excise tax on cigarette price. The change in excise taxes is first translated into the implied percentage change in price. The prevalence elasticity is applied to the percentage change in price to obtain the percent change in prevalence. In Israel, a pack of cigarettes is 30.00 NIS (7.80 USD), of which $17 \%$ is value added (since October 2015) and $69.03 \%$ is excise taxes. There was an increase of over $10 \%$ in cigarette taxes in Israel between 2002 and 2013 [16]. Incorporating the percentage increase in taxes $[t /(1+t)]$ as amplified through the effect of value added taxes, an increase in taxes from $69 \%$ to $75 \%$ is predicted to increase cigarette prices by $39 \%$.
The effect of combined policies is calculated with all policies reaching their MPOWER targets. The effects are proportionally reduced for each additional policy. Thereby, relatively conservative assumptions are made about the effects of combined policies (e.g., some overlapping effects), and the overall effect is bounded between zero and one.

However, synergies are built into the model through media campaigns that enhance the effect of smoke-free air laws and cessation treatment policies.

\section{Results}

The results are presented in Table 2. The table first presents the initial levels for smoking prevalence (by gender) and the total number of smokers. Based on the current level of smoking (24.5\% among males and $13.2 \%$ among females), the number of smokers is 1.1 million in 2014. Based on numbers of smokers, the number of smoking-attributable deaths is projected as 550 thousand (350 thousand male and 200 thousand female) as a lower estimate and 710 thousand (455 thousand male and 255 thousand female) as an upper estimate of the smokers alive in 2014.

The table also shows the effects of each policy individually and in combination. The effects are projected as short and long-term percentage reductions in smoking prevalence and the long-term effects on the number of smokers and smoking-attributable deaths.

- Increasing excise cigarette taxes from its current level of $69 \%$ to $75 \%$ of price will reduce male and female smoking prevalence by $5.9 \%$ within 5 years, increasing to $11.7 \%$ in 40 years, and will avert between 64 and 83 thousand premature deaths.

- Comprehensive smoke-free air laws that made all worksites, restaurants, bars and other public places smoke-free along with stronger enforcement will reduce male and female smoking prevalence by $4.6 \%$ in five years, increasing to $5.8 \%$ in 40 years, and will avert between 32 and 41 thousand premature deaths.

- A well-publicized, comprehensive cessation policy that included a national quitline along with financial full coverage of all treatments will reduce smoking prevalence by $2.6 \%$ in 5 years, increasing $6.5 \%$ in 40 years, and will avert between 35.5 and 46 thousand premature deaths.

- A high level media campaign will reduce smoking prevalence by $5.5 \%$ in 5 years, increasing to $6.6 \%$ in 40 years, and will avert between 36 and 47 thousand premature deaths.

- Pictorial health warnings that cover $50 \%$ of the cigarette package will reduce smoking prevalence by $2 \%$ in 5 years, increasing to $4 \%$ in 40 years, and will prevent between 22 and 28 thousand premature deaths. 
Table 2 Policy effects by MPOWER policy, individual and total: Israel

\begin{tabular}{|c|c|c|c|c|c|c|c|c|c|}
\hline \multirow[t]{2}{*}{ Current levels } & \multicolumn{2}{|c|}{ Smoking prevalence } & \multirow[t]{2}{*}{ Number of smokers } & \multicolumn{3}{|c|}{ Projected deaths of smokers (lower) } & \multicolumn{3}{|c|}{ Projected deaths of smokers (upper) } \\
\hline & Male & Female & & Male & Female & Total & Male & Female & Total \\
\hline Year 2014 & $24.5 \%$ & $13.2 \%$ & $1,093,088$ & 349,468 & 197,076 & 546,544 & 454,308 & 256,199 & 710,507 \\
\hline \multirow[t]{2}{*}{ Original policy } & $\begin{array}{l}\text { Short-term } \\
\text { effect size }\end{array}$ & $\begin{array}{l}\text { Long-term } \\
\text { effect size }\end{array}$ & $\begin{array}{l}\text { Reduction in number } \\
\text { of smokers }\end{array}$ & \multicolumn{3}{|c|}{$\begin{array}{l}\text { Reduction in smoking attributable } \\
\text { deaths (lower) }\end{array}$} & \multicolumn{3}{|c|}{$\begin{array}{l}\text { Reduction in smoking attributable } \\
\text { deaths (upper) }\end{array}$} \\
\hline & & & & Male & Female & Total & Male & Female & Total \\
\hline \multicolumn{10}{|c|}{ Protect through Smoke-free Air Laws } \\
\hline Moderate & $-4.6 \%$ & $-5.8 \%$ & 63,403 & 20,270 & 11,431 & 31,702 & 26,352 & 14,860 & 41,212 \\
\hline \multicolumn{10}{|c|}{ Offer Cessation Treatments } \\
\hline Moderate & $-2.6 \%$ & $-6.5 \%$ & 70,918 & 22,673 & 12,786 & 35,459 & 29,475 & 16,622 & 46,097 \\
\hline \multicolumn{10}{|c|}{ Mass Media Campaigns } \\
\hline Low & $-5.5 \%$ & $-6.6 \%$ & 72,144 & 23,065 & 13,007 & 36,072 & 29,984 & 16,909 & 46,893 \\
\hline \multicolumn{10}{|c|}{ Warnings on Cigarette Packages } \\
\hline Moderate & $-2.0 \%$ & $-4.0 \%$ & 43,724 & 13,979 & 7,883 & 21,862 & 18,172 & 10,248 & 28,420 \\
\hline \multicolumn{10}{|c|}{ Enforcement of Marketing Restrictions } \\
\hline Low-moderate & $-4.4 \%$ & $-5.7 \%$ & 62,525 & 19,990 & 11,273 & 31,262 & 25,986 & 14,655 & 40,641 \\
\hline \multicolumn{10}{|c|}{ Raise Cigarette Taxes } \\
\hline Excise Tax $69 \%$ & $-5.9 \%$ & $-11.7 \%$ & 127,969 & 40,913 & 23,072 & 63,984 & 26,593 & 14,997 & 83,180 \\
\hline \multicolumn{10}{|l|}{ Combined Policies } \\
\hline & $-22.6 \%$ & $-34.3 \%$ & 374,408 & 119,701 & 67,503 & 187,204 & 155,611 & 87,754 & 243,365 \\
\hline
\end{tabular}

Notes: Pre-policy smoking prevalence. Lower and upper bounds for the long-term effect size and the reduction in smoking-attributable deaths can be obtained using the ranges for sensitivity analysis from provided Pre-policy

in Table 1
Smoking-attributable deaths are based on relative risks from high income nations [22] 
- A well-enforced comprehensive ban of direct and indirect advertising (including tobacco products) will reduce smoking prevalence by $4.4 \%$ in 5 years, increasing to $5.7 \%$ in 40 years, and will prevent between 31 and 41 thousand premature deaths.

With the stronger set of policies consistent with FCTC recommendation as specified in MPOWER, the model projects that smoking prevalence can be reduced by $23 \%$ within 5 years increasing to $34 \%$ within 40 years. As a result, between 187 thousand (120 thousand male and 67 thousand female) and 240 thousand (157 thousand male and 88 thousand female) premature deaths of current smokers alive in 2015 are projected to be averted.

\section{Discussion}

Among smokers alive in 2014 in Israel, between 550 and 710 thousand premature deaths are predicted. This demonstrates the urgent need for strong policies to reduce tobacco use. Abridged Simsmoke provides estimates of reductions in smoking prevalence, and the resultant number of smoking-attributable deaths which would be avoided, if MPOWER policies were fully implemented [12]. With a complete implementation of policies, Israel is predicted to reach the goal of reducing smoking rates by $22 \%$ in the next 5 years and by $34 \%$ in forty years. As a consequence, between 187 thousand and 243 thousand premature deaths will be averted. The model indicates that increased cigarette taxes, stronger and better enforced smoke-free air laws, and media campaigns and marketing restrictions can play an important role. To a lesser extent, bolder and graphic health warnings and more comprehensive provision of cessation treatments will also contribute to decreasing the burden of tobaccorelated mortality.

Abridged SimSmoke has been developed based on an extensively validated simulation model and provides support for our estimates. To explicitly consider the predictions of the abridged model, we have compared predictions from Abridged SimSmoke for nine countries that have reached MPOWER goals, including Finland and Italy, to results from the complete SimSmoke model for or those countries and found that the results predicted by Abridged SimSmoke for smoking prevalence and deaths were reasonably close to the reported findings from the complete model [10]. Nevertheless, the findings from Abridged SimSmoke should be interpreted in light of the model's limitations.

Abridged SimSmoke does not incorporate future changes in demographics or smoking prevalence that may reflect the effect of previously implemented policies. The abridged model utilizes smoking prevalence data from 2014 as the basis for estimates of the number of smokers and expected deaths due to smoking among current smokers. The model only attempts to incorporate the effects of stronger future policies on those who were smokers in that survey year. It does not incorporate changes in smoking trends, including those that may be influenced by changes in policies implemented prior to that year, or by smoking cessation which may occur spontaneously over time, as indicated by patterns of declining smoking prevalence among older adults [21].

Difference in smoking patterns between the Jewish and Arab population (Age adjusted estimates: Jewish males: $23.1 \%$, Jewish females: $14.0 \%$, Arab males: 46.6.\%, Arab females: $6.1 \%$ ) [21] are not addressed, due to a lack of sufficient information to distinguish differences in relative risks and differences in policy effects among these populations. Further research is warranted.

The model does not incorporate the effects of the unborn, youth, and young adults who will initiate smoking in future years (in the absence of strong policies). Therefore, failure to incorporate cessation of current smokers may be offset by the benefits of newly implemented policies on reducing future initiation. While not considered in our analysis, substantial additional gains can be expected through the effects of policies on the young. In particular, SimSmoke attributes more than twice the effect of tax increases on those under the age of 24 as for those ages 25 and above [31, 32]. Further, advertising restrictions are expected to have a $50 \%$ greater effect on those below age 24 $[3,33]$. The implementation and enforcement of bans on all smoking in the workplace can also be expected to have an important impact on those newly entering the workforce. These estimates would imply a $25-35 \%$ overall reduction in smoking initiation. We estimate between 550,000 and 710,000 deaths due to smoking. Ginsburg and Geva [34, 35] estimated the number of smokingattributable deaths at 7,400 per year, implying about 375,000 deaths over 50 years. However, there are important differences between the two methods (e.g., Ginsburg and Geva used deaths by cause vs our use of total mortality, and our upper level estimates are based on higher levels of risks found in the more recent studies [23, 24]). Further study is warranted to examine the composition of deaths by cause and the number of deaths over time by age and gender. In addition, we focused on mortality, but additional costs are associated with morbidity and productivity loss due to premature death. In addition to the 7000 and 7850 smoking-attributable deaths each year, Ginsburg and Geva [34,35] estimated 319,231 active and 356,601 total smoking attributable hospital days and 1678 million NIS (\$482 million) in total health service costs, 0.2 $\%$ of GNP. With productivity losses, smoke related costs overall were 3,587 million NIS ( $\$ 1,030$ million), $0.41 \%$ of GNP. We did not include deaths due to second handsmoke in the model. Globally, secondhand smoke is responsible for $1 \%$ of total mortality and $0.7 \%$ of the 
worldwide disease burden [36]. We also did not address the economic costs or pain and suffering, caused by tobacco smoke exposure, such as increases in rates of child respiratory disease, low birthweight, sudden infant death syndrome, and pre-term birth [37]. A study of parentally-reported exposure of infants aged $0-2$ between 2009-2012 found that 31.5 \% (Jewish infants: $24.8 \%$, Arab infants: 52.0) of infants were at least occasionally exposed to tobacco smoke [21]. A reduction in smoking rates would also decrease exposure of children to smoking.

Another limitation is that the effect of policies is subject to uncertainty. We have provided ranges of the effect sizes in Table 1. In addition, the model only applies to cigarettes and thus does not incorporate other tobacco products such as pipes, cigars, water pipes, and smokeless tobacco. If tax increases and other policies target cigarette smokers exclusively, there may be a substitution toward greater usage of other tobacco products. By directing policies (e.g., media campaigns) at all tobacco products, some of this substitution may be avoided. E-cigarettes potentially provide a lower harm alternative to smoking and therefore may either accelerate or attenuate reductions in net population smoking prevalence depending on how they influence smoking patterns (e.g, initiation and cessation rates) and related policies and practices [38].

Abridged SimSmoke has been developed to use data from the biennial WHO MPOWER Reports. The MPOWER policy data are restricted to a specific set of policies and definitions. The model does not consider policies directed at price minimizing behavior [39], enforcement against smuggling [40], product regulation (e.g., nicotine reduction) [41, 42], plain packaging [43, 44], harm reduction policies (i.e., encouraging substitution of less harmful alternatives to cigarettes) $[45,46]$ and youth access policies [47]. These other policies have also been shown to be effective and are likely to be needed for Israel to approach the endgame for smoking cigarettes.

We did not consider the costs of the interventions relative to their effectiveness. Studies of specific policies have generally found that tobacco control policies are cost effective [48-50]. Taxing policy and health warnings, both of which involve minimal costs, are particularly cost effective. Further study is warranted on the costs of implementation and the cost savings that would specifically be incurred in Israel.

Abridged SimSmoke shows that the required MPOWER tobacco control policies will save lives and eventually decrease tobacco use. The model enables the user to consider policies individually and in combination to observe how policies in different combinations lead to differing rates of reductions in smoking prevalence and smokingattributable deaths. It also translates empirical information into a user-friendly format that can be easily interpreted. This is particularly important given difficulties inherent in tobacco-control policy making, which may include local and global tobacco industry interference $[51,52]$, lack of public knowledge of the harms of tobacco smoke exposure [12] and underestimation by policy makers regarding public support for smoke-free public places [29, 53].

Abridged SimSmoke for Israel shows an urgent need for strengthening comprehensive and proven effective policies and practices to combat and ultimately eliminate the wholly preventable deaths and chronic disease burdens and disabilities caused by tobacco use, primarily driven by the smoking of cigarettes $[54,55]$.

\section{Acknowledgements and Funding}

David Levy received funding from Truth Initiative and the Cancer Intervention and Surveillance Modeling Network (CISNET) of the Division of Cancer Control and Prevention Sciences, National Cancer Institute, US National Institute of Health under grant UO1-CA97450-02 for general development of the SimSmoke model.

\section{Availability of data and materials}

Not applicable.

\section{Authors' contributions}

DTL and JKL drafted the initial manuscript. DA and LJR provided information and extensively edited the entire manuscript and LJR drafted sections of the manuscript. JKL performed the research on the legislation and taxation and helped developed the model. DTL supervised development of the model. All authors read and approved the final manuscript.

\section{Competing interests}

The authors declare that they have no competing interests.

\section{Authors' information}

'David T. Levy, Department of Oncology, Lombardi Comprehensive Cancer Center, Georgetown University Medical Center, Washington, DC, USA. He is a Professor of Oncology at Georgetown University. He has been Principal Investigator on grants from the US National Cancer Institute, US Centers for Disease Control, US National Institute on Drug Abuse, Robert Wood Johnson Foundation, the World Health Organization. He has published over 200 articles, including 50 articles related to the SimSmoke model. He has acted as consultant to the Institute of Medicine, the World Health Organization, the Rockefeller Foundation, and more than 40 countries on tobacco control and on obesity policy.

${ }^{2}$ David B. Abrams, PhD Dept. of Health, Behavior and Society, Johns Hopkins Bloomberg School of Public Health, Baltimore, MD, USA Department of

Oncology, Lombardi Comprehensive Cancer Center, Georgetown University Medical Center, Washington, DC, USA.

He directed the U.S. National Institutes of Health (NIH) Office of Behavioral and Social Sciences Research (OBSSR) and was President of the Society of Behavioral Medicine. He has published over 250 articles and been an investigator on many NIH grants, including The Center for Evaluation and Coordination of Training and Research in Tobacco Regulatory Science. His awards include: Society of Behavioral Medicine Distinguished Scientist Award; American Academy of Health Behavior Research Laureate Award; Book of the Year Award for Tobacco Dependence Treatment Handbook: A Guide to Best Practices; and the Joseph W. Cullen Memorial Award for lifetime contributions to Tobacco Research, American Society for Preventive Oncology.

${ }^{3}$ Jeffrey Levy, MA, Washington, DC teaches Algebra in a Public School in Virginia and acts as a research assistant for his father.

${ }^{4}$ Laura Rosen, PhD, Department of Health Promotion, School of Public Health, Sackler Faculty of Medicine, Tel Aviv University, Ramat Aviv, Israel. LJR chairs the Dept. of Health Promotion at the School of Public Health at Tel Aviv University. Her primary area of research is tobacco control. She was National Coordinator for Healthy Israel 2020 from 2005-2006, served as Senior Consultant to the Ministry of Health on the initiative from 2006-2007, and chaired the Tobacco Control 2020 Subcommittee. She was also a member of the Public Committee for Reduction of Smoking and its Harm. 
She is a member of the Israeli Association for Smoking Prevention, a temporary advisor to the European Advisory Committee on Health Research, and is on the Steering Committee of EvipNet, a WHO-sponsored initiative to promote the use of evidence in policy-making. She has received research awards from the Flight Attendant Medical Research Institute, the Israel National Institute for Health Policy, the Ministry of Health, and the Israel Cancer Association. She teaches Israel's first (and to date only), academic course on tobacco control, and initiated and runs the Tobacco Control Research Forum at Tel Aviv University.

\section{Ethics approval and consent to participate}

This research, based entirely on available public data, did not require approval of an ethics committee.

\section{Author details}

${ }^{1}$ Department of Oncology, Lombardi Comprehensive Cancer Center, Georgetown University Medical Center, Washington, DC, USA. ${ }^{2}$ Department of Health, Behavior and Society, Johns Hopkins Bloomberg School of Public Health, Baltimore, MD, USA. ${ }^{3}$ Silver Spring, MD, USA. ${ }^{4}$ Department of Health Promotion, School of Public Health, Sackler Faculty of Medicine, Tel Aviv University, Ramat Aviv, Israel.

\section{Received: 2 February 2016 Accepted: 12 August 2016}

\section{Published online: 15 September 2016}

\section{References}

1. WHO discussion paper: a comprehensive global monitoring framework and voluntary global targets for the prevention and control of NCDs. comprehensive global monitoring framework including indicators and a set of voluntary global targets for the prevention and control of NCDs. [http://www.who.int/nmh/events/2012/consultation_april_2012/en/] Accessed 30 Aug 2016

2. World Health Organization. WHO Report on the Global Tobacco Epidemic 2008: The MPOWER package. Geneva: World Health Organization; 2008. http://www.who.int/tobacco/mpower/2008/en/. Accessed 30 Aug 2016.

3. Levy DT, Gitchell JG, Chaloupka F. The Effects of Tobacco Control Policies on Smoking Rates: A Tobacco Control Scorecard. J Public Health Manag Pract. 2004;10:338-51.

4. Levy D, de Almeida LM, Szklo A. The Brazil SimSmoke policy simulation model: the effect of strong tobacco control policies on smoking prevalence and smoking-attributable deaths in a middle income nation. PLoS Med. 2012;9(11), e1001336.

5. Levy D, Rodriguez-Buno RL, Hu TW, Moran AE. The potential effects of tobacco control in China: projections from the China SimSmoke simulation model. BMJ. 2014:348:g1134.

6. Levy D, Zaloshjna E, Blackman K, Chaloupka F, Fong GT. The Role of Tobacco Control Policies in Reducing Smoking and Deaths Caused by Smoking in the Eighteen Nations with the Largest Smoking Burden. Rockville: National Cancer Institute Monograph; in press.

7. Levy DT, Benjakul S, Ross H, Ritthiphakdee B. The role of tobacco control policies in reducing smoking and deaths in a middle income nation: results from the Thailand SimSmoke simulation model. Tob Control. 2008;17(1):53-9.

8. Levy DT, Blackman K, Currie LM, Mons U. Germany SimSmoke: the effect of tobacco control policies on future smoking prevalence and smokingattributable deaths in Germany. Nicotine Tob Res. 2013;15(2):465-73.

9. Levy DT, Currie L, Clancy L. Tobacco control policy in the UK: blueprint for the rest of Europe? Eur J Public Health. 2012;23(2):201-6.

10. Levy DT, Huang AT, Currie LM, Clancy L. The benefits from complying with the framework convention on tobacco control: a SimSmoke analysis of 15 European nations. Health Policy Plan. 2014;29(8):1031-42.

11. Levy D, Currie L, Clancy L. Tobacco Control Policy in the United Kingdom: Blueprint for the Rest of Europe? Eur J Public Health. 2012;epub.

12. Levy DT, Fouad H, Levy J, Dragomir AD, El Awa F. Application of the Abridged SimSmoke model to four Eastern Mediterranean countries. Tob Control. 2015

13. Rosen LJ, Peled-Raz M. Tobacco policy in Israel: 1948-2014 and beyond. Isr J Health Policy Res. 2015;4:12.

14. Rosen L, Rosenberg E, McKee M, Gan-Noy S, Levin D, Mayshar E, Shacham G, Borowski J, Nun GB, Lev B, et al. A framework for developing an evidence-based, comprehensive tobacco control program. Health Res Policy Syst. 2010;8:17.

15. Baron-Epel O, Shalata W, Hovell MF. Waterpipe Tobacco Smoking in Three Israeli Adult Populations. Isr Med Assoc J. 2015;17(5):282-7.
16. Feldman I, Donchin M, Levine H. A smoke-free medical campus in Jerusalem: data for action. Isr J Health Policy Res. 2016;5:20.

17. Glantz SA. Israel is failing to protect its citizens from secondhand smoke: underestimating public support. Isr J Health Policy Res. 2013;2(1):24.

18. Schroeder SA. Commentary on a smoke-free medical campus in Jerusalem: data for action. Isr J Health Policy Res. 2016:5:27.

19. Baron-Epel O, Satran C, Cohen V, Drach-Zehavi A, Hovell MF. Challenges for the smoking ban in Israeli pubs and bars: analysis guided by the behavioral ecological model. Isr J Health Policy Res. 2012;1(1):28.

20. Satran C, Drach-Zahavy A, Hammond SK, Baron-Epel O. Implementing the ban on smoking in Israeli pubs: measuring airborne nicotine and enforcement by local authorities. Glob Health Promot. 2014;21(2):7-14

21. Health Services Branch, Israel Ministry of Health. Health Minister's Report to the Knesset on Smoking 2014. 2015. [http://www.health.gov.l/PublicationsFiles/ smoking 2014.pdf]. Accessed 30 Aug 2016.

22. Doll R, Peto R, Boreham J, Sutherland I. Mortality in relation to smoking: 50 years' observations on male British doctors. BMJ. 2004:328(7455):1519.

23. Kenfield SA, Stampfer MJ, Rosner BA, Colditz GA. Smoking and smoking cessation in relation to mortality in women. Jama. 2008:299(17):2037-47.

24. Thun MJ, Carter BD, Feskanich D, Freedman ND, Prentice R, Lopez AD, Hartge P, Gapstur SM. 50-year trends in smoking-related mortality in the United States. N Engl J Med. 2013;368(4):351-64.

25. Levy DT, Huang AT, Currie LM, Clancy L. The benefits from complying with the framework convention on tobacco control: a SimSmoke analysis of 15 European nations. Health Policy Plan. 2013.

26. Levy DT, Currie L, Clancy L. Tobacco control policy in the UK: blueprint for the rest of Europe? Eur J Public Health. 2013;23(2):201-6.

27. World Factbook [http://www.theodora.com/wfb/abc_world_fact_book.html]. Accessed 30 Aug 2016

28. Data and Statistics [(http://data.worldbank.org/indicator/SL.TLF.CACT.ZS/ countries/IL?display=graph)]. Accessed 30 Aug 2016.

29. Rosen U, Rier DA, Schwartz R, Oren A, Kopel A, Gevman A, Zeller M Connolly G. Public support for smoke-free areas in Israel: a case for action. Health Policy. 2012;106(2):161-8.

30. Rosen $\amalg$, Zucker D, Rosenberg H, Connolly G. Secondhand smoke in Israeli bars, pubs and cafes. Isr Med Assoc J. 2008;10(8-9):584-7.

31. Chaloupka FJ, Straif K, Leon ME, Working Group IAfRoC. Effectiveness of tax and price policies in tobacco control. Tob Control. 2011:20(3):235-8.

32. Levy DT, Cummings KM, Hyland A. Increasing taxes as a strategy to reduce cigarette use and deaths: results of a simulation model. Prev Med. 2000; 31(3):279-86.

33. Levy DT, Lindblom EN, Fleischer NL, Thrasher J, Mohlman MK, Zhang Y, Monshouwer K, Nagelhout GE. Public Health Effects of Restricting Retail Tobacco Product Displays and Ads. Tob Regul Sci. 2015;1(1):61-75.

34. Ginsberg GM, Geva H. The burden of smoking in Israel-attributable mortality and costs (2014). Isr J Health Policy Res. 2014;3:28.

35. Ginsberg GM, Rosenberg $E$, Rosen L. Issues in estimating smoking attributable mortality in Israel. Eur J Public Health. 2010;20(1):113-9.

36. Oberg M, Jaakkola MS, Woodward A, Peruga A, Pruss-Ustun A. Worldwide burden of disease from exposure to second-hand smoke: a retrospective analysis of data from 192 countries. Lancet. 2011:377(9760):139-46.

37. USDHHS. The health consequences of second-hand smoke: A report of the Surgeon General. Atlanta: U.S. Department of Health and Human Services CfDCaP, National Center for Chronic Disease Prevention and Health Promotion, Office on Smoking and Health; 2006.

38. Abrams DB, Niaura R. The importance of science-informed policy and what the data really tell us about e-cigarettes. Isr J Health Policy Res. 2015:4:22.

39. Pesko MF, Licht AS, Kruger JM. Cigarette price minimization strategies in the United States: price reductions and responsiveness to excise taxes. Nicotine Tob Res. 2013;15(11):1858-66.

40. Joossens $L$, Raw M. From cigarette smuggling to illicit tobacco trade. Tob Control. 2012;21(2):230-4.

41. Cheung YT, Lam TH, Leung DY, Abdullah AS, Chan SS. Nicotine replacement therapy to aid gradual cessation in smokers with no intention to quit: Association between reduction quantity and later abstinence. Prev Med Rep. 2015;2:196-201

42. Hatsukami DK, Kotlyar M, Hertsgaard LA, Zhang Y, Carmella SG, Jensen JA, Allen SS, Shields PG, Murphy SE, Stepanov I, et al. Reduced nicotine content cigarettes: effects on toxicant exposure, dependence and cessation. Addiction. 2010;105(2):343-55. 
43. Smith CN, Kraemer JD, Johnson AC, Mays D. Plain packaging of cigarettes: do we have sufficient evidence? Risk Manag Healthc Policy. 2015;8:21-30.

44. Stead M, Moodie C, Angus K, Bauld L, McNeill A, Thomas J, Hastings G, Hinds K, O'Mara-Eves A, Kwan I, et al. Is consumer response to plain/ standardised tobacco packaging consistent with framework convention on tobacco control guidelines? A systematic review of quantitative studies. PLoS One. 2013;8(10), e75919.

45. Abrams DB. Promise and peril of e-cigarettes: can disruptive technology make cigarettes obsolete? JAMA. 2014;311(2):135-6.

46. Levy DT, Cummings KM, Villanti AC, Niaura R, Abrams DB, Fong GT, Borland R. A framework for evaluating the public health impact of e-cigarettes and other vaporized nicotine products. Addiction. 2016.

47. DiFranza JR. Which interventions against the sale of tobacco to minors can be expected to reduce smoking? Tob Control. 2012;21(4):436-42.

48. Over EA, Feenstra TL, Hoogenveen RT, Droomers M, Uiters E, van Gelder BM. Tobacco control policies specified according to socioeconomic status: health disparities and cost-effectiveness. Nicotine Tob Res. 2014;16(6):725-32.

49. Ranson MK, Jha P, Chaloupka FJ, Nguyen SN. Global and regional estimates of the effectiveness and cost-effectiveness of price increases and other tobacco control policies. Nicotine Tob Res. 2002;4(3):311-9.

50. Verguet S, Gauvreau CL, Mishra S, MacLennan M, Murphy SM, Brouwer ED, Nugent RA, Zhao K, Jha P, Jamison DT. The consequences of tobacco tax on household health and finances in rich and poor smokers in China: an extended cost-effectiveness analysis. Lancet Glob Health. 2015;3(4):e206-16.

51. Smith KE, Savell E, Gilmore AB. What is known about tobacco industry efforts to influence tobacco tax? A systematic review of empirical studies. Tob Control. 2013;22(2):144-53.

52. Yach $D$, Bettcher $D$. Globalisation of tobacco industry influence and new global responses. Tob Control. 2000;9(2):206-16.

53. Connolly GN. How society treats smoking. Isr J Health Policy Res. 2012;1 (1):29.

54. Levy DT, Bauer JE, Lee HR. Simulation modeling and tobacco control: creating more robust public health policies. Am J Public Health. 2006;96(3):494-8.

55. Levy DT, Chaloupka F, Gitchell J, Mendez D, Warner KE. The use of simulation models for the surveillance, justification and understanding of tobacco control policies. Health Care Manag Sci. 2002;5(2):113-20.

\section{Submit your next manuscript to BioMed Central and we will help you at every step:}

- We accept pre-submission inquiries

- Our selector tool helps you to find the most relevant journal

- We provide round the clock customer support

- Convenient online submission

- Thorough peer review

- Inclusion in PubMed and all major indexing services

- Maximum visibility for your research

Submit your manuscript at www.biomedcentral.com/submit

) Biomed Central 